\title{
Inflammation Induced by Natural Neuronal Death and LPS Regulates Neural Progenitor Cell Proliferation in the Healthy Adult Brain
}

\author{
DTracy A. Larson, ${ }^{1,2}$ Yekaterina Tokareva, ${ }^{2}$ Marianne Meritt Cole, ${ }^{3}$ and ${ }^{\circledR}$ Eliot A. Brenowitz ${ }^{2,3}$
}

https://doi.org/10.1523/ENEURO.0023-20.2020

${ }^{1}$ Department of Biology, University of Virginia, Charlottesville, Virginia 22904, ${ }^{2}$ Department of Biology, University of Washington, Seattle, Washington 98195-1800, and ${ }^{3}$ Department of Psychology, University of Washington, Seattle, Washington 98195-1525

\begin{abstract}
Inflammation is typically considered a negative response to injury or insult; however, recent advances demonstrate that inflammatory cells regulate development, plasticity, and homeostasis through anticytotoxic, progenerative responses. Here, we extend analyses of neuroinflammation to natural neurodegenerative and homeostatic states by exploiting seasonal plasticity in cytoarchitecture of the avian telencephalic song control nucleus, high vocal center [HVC (proper name)], in the songbird Gambel's white-crowned sparrow (Zonotrichia leucophrys gambelii). We report that local injection of the endotoxin lipopolysaccharide into HVC of birds in both breeding (high circulating testosterone level) and nonbreeding (low circulating testosterone level) conditions increased neural progenitor cell proliferation in the nearby but distinct ventricular zone. Additionally, we found that oral administration of the anti-inflammatory drug minocycline during seasonal regression of HVC reduced microglia activation in HVC and prevented the normal proliferative response in the ventricular zone to apoptosis in HVC. Our results suggest that local neuroinflammation positively regulates neural progenitor cell proliferation and, in turn, contributes to the previously described repatterning of HVC cytoarchitecture following seasonally induced neuronal loss.
\end{abstract}

Key words: apoptosis; neural plasticity; neural progenitor cell; neuroinflammation; sex steroids; songbird

\section{Significance Statement}

We demonstrate that natural reactive neurogenesis, or the birth of new neurons in the adult brain following non-injury-induced neuronal loss, is depressed with oral administration of the anti-inflammatory drug minocycline. Minocycline-an inhibitor of microglia activation-prevents reactive neurogenesis following seasonally induced neuronal loss in the avian telencephalic nucleus, high vocal center [HVC (proper name)]. Conversely, local inflammation, induced by microinjecting endotoxin directly into HVC, increases neural progenitor cell proliferation in the adjacent ventricular zone, which supplies HVC with new neurons. These findings contribute to the emerging role that neuroinflammatory cells play in regulating adult neurogenesis and promoting circuit homeostasis and regeneration, and establish the avian song control circuit as a useful model for future studies examining mechanisms of neuroinflammation.

\section{Introduction}

Inflammatory responses are important for debris and pathogen clearance, tissue repair, and in some contexts,

Received January 26, 2020; accepted May 12, 2020; First published May 18, 2020.

The authors declare no competing financial interests. protection from future insults. Inflammation has been classically viewed as detrimental. Yet, emerging evidence indicates that inflammatory cells play critical roles in

Author contributions: T.A.L. and E.A.B. designed research; T.A.L., Y.T., and M.M.C. performed research; T.A.L. analyzed data; T.A.L. and E.A.B. wrote the paper. 
establishing tissue pattern; plasticity of cell morphology and behavior; and maintenance of cellular, tissue, and organ homeostasis (Hammond et al., 2018). The effects of inflammation depend on several factors including the following: the location and cellular heterogeneity of the tissue in which inflammation occurs (Marshall et al., 2014); the duration of the inflammatory event (Kohman and Rhodes, 2013); and the age, sex, and hormonal status of the individual (Villa et al., 2016). Consequently, a shift away from positive protective inflammatory effects underlying the processes of development, plasticity, and homeostasis toward more detrimental cytotoxic inflammation likely contributes to the pathologic consequences of many diseases including depression, Alzheimer's disease, epilepsy, and multiple sclerosis, among others (Wynn et al., 2013).

Within the CNS, inflammatory cells can have seemingly contradictory effects on mature neuronal survival, glial support and scarring, circuit structure, neural progenitor cell (NPC) proliferation and the survival and function of new neurons (Larson, 2018). The impact of neuroinflammation on NPCs and their progeny depends on the phenotypic state of the responding cells-typically astroglia and microglia. For example, in the healthy brain, "resting" or ramified microglia play a beneficial role by phagocytosing excess NPC progeny to maintain proper neuronal number (Sierra et al., 2010). Following tissue damage, microglia become polarized and respond through a continuum of functional states. The impact of these functional states ranges between "negative" cytotoxic inflammation (Prinz and Priller, 2014) and "positive" resolution through the release of anti-inflammatory cytokines and growth factors (Hu et al., 2012). The dynamic impacts of inflammatory cells in the CNS, together with the fact that not all neurodegeneration is injury or pathogen induced, highlight the need for examining neuroinflammation within the contexts of naturally occurring neuronal death and maintenance of homeostasis in otherwise healthy adult brains.

Seasonal regression of the avian telencephalic song nucleus high vocal center [HVC (proper name); Reiner et al., 2004] and its efferent target, the robust nucleus of the arcopallium (RA), provides a unique and valuable model to investigate inflammatory modulation of NPC proliferation during stable states and after nonpathologic neural

This research was supported by Department of Health and Human Services (HHS) | National Institutes of Health (NIH) | National Institute of Mental Health Grant R01-MH-53032 and HHS | NIH | National Institute of Neurological Disorders and Stroke Grant R01-NS-075331 to E.A.B.; HHS | NIH | National Institute of General Medical Sciences Grant T32-GM-007270; Washington Research Foundation Hall Fellowship; and University of Virginia Startup Funds to T.A.L.

Acknowledgments: We thank Karin Lent, Kristen Richards, Nivretta Thatra, and Matthew Wolkoff for assistance. We also thank David Parichy for comments.

Correspondence should be addressed to Tracy A. Larson at larson.tracy@ virginia.edu.

https://doi.org/10.1523/ENEURO.0023-20.2020

Copyright (C) 2020 Larson et al.

This is an open-access article distributed under the terms of the Creative Commons Attribution 4.0 International license, which permits unrestricted use, distribution and reproduction in any medium provided that the original work is properly attributed. degeneration (Fig. 1A). In adult male Gambel's whitecrowned sparrows (Zonotrichia leucophrys gambelii), HVC neuronal number changes seasonally (Smith et al., 1997). Within 1 week of breeding condition onset, HVC growth stabilizes with as many as 68,000 new neurons incorporated into the existing 100,000 mature neurons (Tramontin et al., 2000). Within $4 \mathrm{~d}$ of transition from breeding to nonbreeding conditions, an equal number of HVC neurons die via caspase-dependent cell death (Thompson and Brenowitz, 2008). HVC cell death increases proliferation in the adjacent, but distinct ventral ventricular zone (vVZ; Larson et al., 2014), which supplies HVC with new neurons (Scott and Lois, 2007). Proliferation in the $\mathrm{VVZ}$ occurs primarily through rapidly dividing radial glial neural progenitor cells (Scott and Lois, 2007), but also presumably includes neural stem cells, albeit at slower and lower rates. Both the rapid addition of new neurons and the natural reactive neurogenesis in the nearby vVZ precede a return of HVC to breeding and nonbreeding homeostatic states (Larson et al., 2014). The natural plasticity in neuron number, with accompanying changes in arborization and electrical signaling (DeVoogd and Nottebohm, 1981; Meitzen et al., 2007), contributes to a biologically relevant and plastic behavior: the production of learned song (Meitzen et al., 2009).

Because HVC neuronal loss, reactive neurogenesis, and subsequent return to homeostasis occur robustly and without prior neural insult, white-crowned sparrows are useful for examining the processes and mechanisms by which neuroinflammation modulates NPC under nonpathologic conditions in the adult brain. We report that the induction of inflammation locally within HVC rapidly increased NPC proliferation in the VVZ. Alternatively, decreasing microglia activation following natural neuronal loss in HVC reduced the reactive increase in NPC proliferation. Our work provides the first evidence for inflammatory modulation of NPC proliferation under a natural, noninjury-induced neurodegenerative state in the intact adult brain.

\section{Materials and Methods}

Animals. Male Gambel's white-crowned sparrows were collected in eastern Washington during seasonal migration. Upon capture, all birds were aged with a minimum age based on plumage coloration. Birds with juvenile plumage (brown crown) were assigned an age of 2 months. Because precise age cannot be determined in whitecrowned sparrows once a bird has attained its adult plumage (black and white crown), all adult birds were assigned a minimum age of 14 months on collection. All birds were housed in indoor aviaries exposed to shortday (ShD) photoperiods (ShDs; $8 \mathrm{~h}$ light, $16 \mathrm{~h}$ dark) for at least 10 weeks to ensure that their reproductive systems had fully regressed, and that the birds would be sensitive to the stimulatory effects of transition to long day photoperiods (LDs; $20 \mathrm{~h}$ light, $4 \mathrm{~h}$ dark) and testosterone (T) treatment. Because age affects levels of cell death and neurogenesis in white-crowned sparrows (Larson et al., 2014), adult male birds were assigned semirandomly to experimental groups with age being the only factor 
A
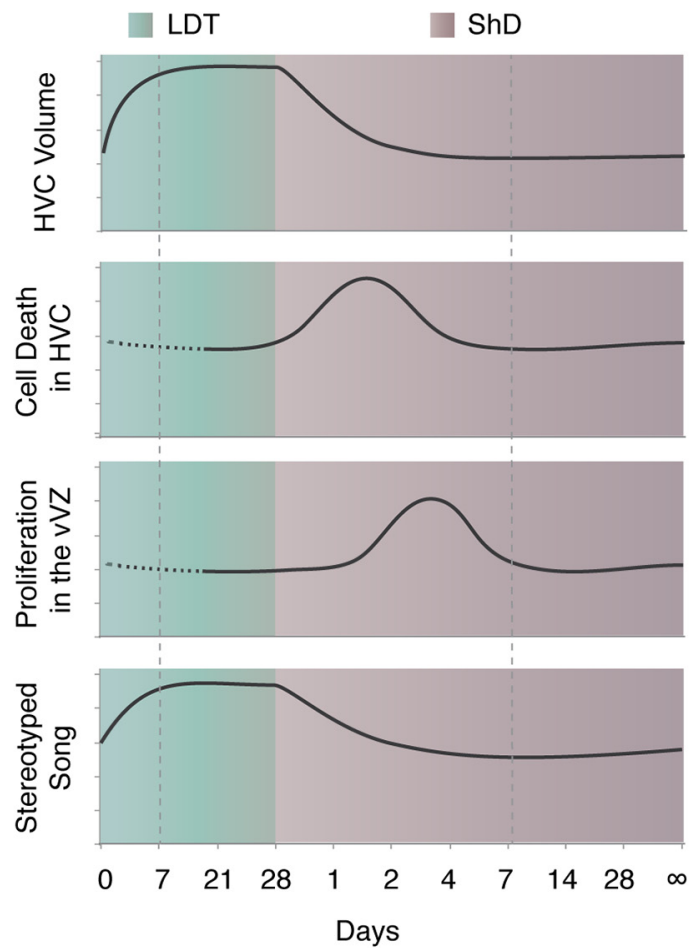

B

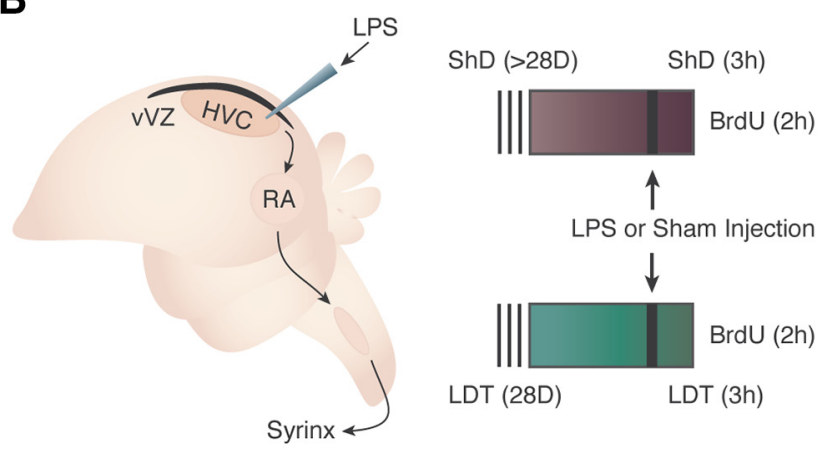

C

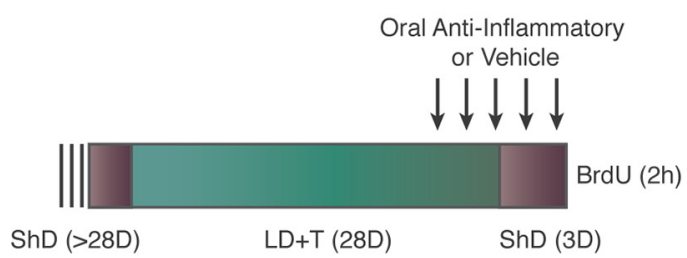

Figure 1. Experimental background and design. A, Seasonal growth and regression of HVC and effects on song stereotypy are illustrated. As white-crowned sparrows transition from breeding (green background) to nonbreeding conditions (purple background), HVC regresses in volume due to cell death. Increased proliferation of NPCs in the VVZ (black strip dorsal to HVC) that gives rise to new HVC neurons follows temporally and is induced by HVC cell death (Larson et al., 2014). Morphology and physiology reaches homeostasis in both breeding and nonbreeding conditions (indicated by dotted box). Dotted line indicates a lack of published data for those time points. $\boldsymbol{B}$, Schematics illustrating the song production circuit and experimental design for testing the role of acute, local inflammation on NPC proliferation. The song production circuit purposely selected and balanced across groups. All experiments followed National Institutes of Health $(\mathrm{NIH})$ animal use guidelines and were approved by the University of Virginia and the University of Washington Institutional Animal Care and Use Committees.

Experimental design. We injected HVC with lipopolysaccharides (LPSs), a lipoglycan endotoxin from the outer membrane of Gram-negative bacteria commonly used to mimic CNS infection and induce microglia activation (Buttini et al., 1996; Hauss-Wegrzyniak et al., 1998). To identify a dose and duration that promoted inflammation but not cell death, we injected LPS of varying concentrations $(0.3,1$, or $2 \mu \mathrm{g}$ in $60 \mathrm{nl}$ of $15 \%$ DMSO, $7 \%$ sodium chloride) into HVC of two birds in ShD conditions for each possible treatment. Briefly, after anesthetizing birds with isoflurane (1.5-2\%), we lowered a glass micropipette into HVC lateral to the intersection of the midsagittal and transverse sinuses $(0.7 \mathrm{~mm}$ ventral, $2.3 \mathrm{~mm})$ and pressure injected LPS or vehicle $(60 \mathrm{nl}$ of $15 \%$ DMSO in $7 \%$ sodium chloride saline). Tissue was collected from two birds for each injected dose of LPS at each of the following survival times: 3, 6, 12, and $24 \mathrm{~h}$. Upon examination of BrdU-immunolabeled and Nissl-stained tissue for VVZ proliferation and pyknotic cells, respectively (methods for staining are described below), we determined that a dose of $1 \mu \mathrm{g}$ injected $3 \mathrm{~h}$ before the termination of the experiment optimally induced NPC proliferation (Fig. $2 A$ ) without inducing cell death beyond baseline levels (Larson et al., 2019) as detected with Nissl staining (Fig. 2B).

Birds were housed in either ShD $(n=11)$ or LD with implantation of a subcutaneous $12 \mathrm{~mm}$ SILASTIC capsule (1.47 mm inner diameter, $1.96 \mathrm{~mm}$ outer diameter) filled with crystalline $\mathrm{T}$ (Sigma-Aldrich) above the scapula [i.e., LD and exogenous T (LDT), $n=18$; Fig. $1 B]$. After $28 \mathrm{~d}$ in ShD or LDT, we injected HVC with LPS $(1 \mu \mathrm{g}$ in $60 \mathrm{nl}$ of $15 \%$ DMSO, saline; ShD, $n=6$; LDT, $n=9$ ). To ensure that the end of the needle track was within HVC, four birds were injected with Life Technologies LPS Alexa Fluor 568 Conjugate $(1 \mu \mathrm{g}$ in $60 \mathrm{nl}$ of $15 \%$ DMSO, saline; Thermo Fisher Scientific). Histologic analysis confirmed that the end of the needle track was in HVC of all four birds (Fig. $3 A$ ). Control birds (ShD, $n=5$; LDT, $n=9$ ) had the needle lowered into HVC with no injection of fluid. One hour following surgery and $2 \mathrm{~h}$ before tissue collection, all birds were injected intraperitoneally with $\mathrm{BrdU}(50 \mathrm{mg} / \mathrm{kg}$;

\section{continued}

consists of HVC (proper name), the RA, and nXIlts, nucleus para-ambiguus. Birds in nonbreeding (ShD; purple) or breeding (LDT; green) condition for $28 \mathrm{~d}$ received LPS through needle microinjection into HVC, while controls received sham injections. To label proliferating NPC, BrdU was administered systemically $1 \mathrm{~h}$ following LPS or sham injection, and $2 \mathrm{~h}$ before tissue harvesting. C, Experimental design to test the necessity of inflammation for reactive neurogenesis following natural cell death in HVC. Birds received oral doses of the anti-inflammatory agent minocycline starting $2 \mathrm{~d}$ before and continuing throughout the 3 d of HVC regression after rapid transition of birds from LDT to ShD conditions. Control birds received oral doses of water. All birds were injected with BrdU to label proliferating NPC $2 \mathrm{~h}$ before tissue harvesting. 
A

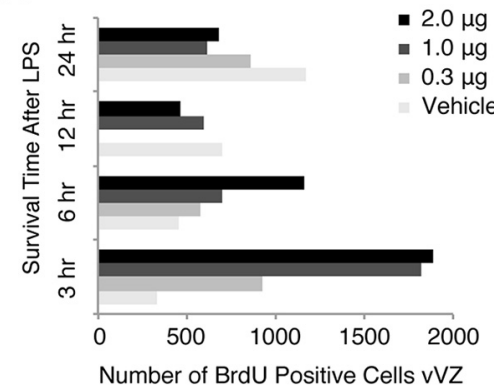

B

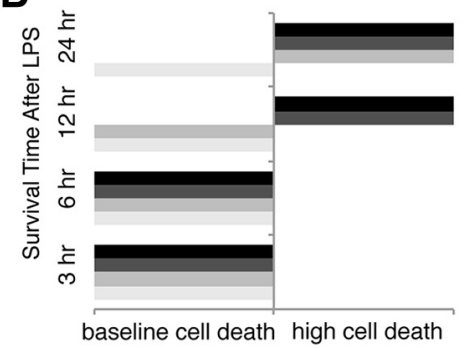

Figure 2. Identification of an LPS injection dose and pulse time that increases VVZ NPC proliferation but does not increase HVC cell death. $\boldsymbol{A}$, BrdU-positive cells in unilateral vVZ following injection of LPS ranging from 0 to $2 \mu \mathrm{g}$ and a survival time of 3$24 \mathrm{~h}$ before tissue harvesting. NPC proliferation appeared to increase as soon as $3 \mathrm{~h}$ following LPS injection for all groups except saline vehicle. Saline appeared to increase the number of BrdU-positive vVZ cells by $24 \mathrm{~h}$ following HVC injection. Each experimental and control group, $n=2$. $\boldsymbol{B}$, Grossly observed cell death in HVC following injection of LPS or vehicle over the time course. LPS appeared to induce cell death as soon as $12 \mathrm{~h}$ following LPS injection in a dose-dependent manner. By $24 \mathrm{~h}$, all doses of LPS induced HVC cell death obviously visible by large numbers of Nissl-stained pyknotic cells. LPS appeared to not induce large quantities of HVC cell death with 3 and 6 h survival times. Because a dose of $1 \mu \mathrm{g}$ of LPS induced a large increase in $v V Z$ proliferation but no cell death after $3 \mathrm{~h}$, we chose this dose and time course for our experiment.

$15 \mathrm{mg} / \mathrm{ml}$ in $15 \%$ DMSO in PBS) to label proliferating NPC and their recent progeny in the VVZ.

We blocked inflammation with an oral anti-inflammatory drug, minocycline, during rapid regression of HVC (Fig. $1 C)$. Minocycline directly inhibits microglia transition to the activated state, and thus indirectly attenuates the innate inflammatory response through decreased TNF- $\alpha$, cytokine, and interleukin production (Giuliani et al., 2005; Kobayashi et al., 2013). All birds were housed in LDT for $28 \mathrm{~d}$ to allow full breeding-like growth of the song control nuclei $(n=21$; Tramontin et al., 2000). To induce regression of HVC, birds had T pellets removed after $28 \mathrm{~d}$ of LDT and were transitioned onto an ShD light schedule overnight ( $n=17$; Larson et al., 2014). Two days before transition (i.e., LDT at $26 \mathrm{~d}$ ), birds began receiving a twicedaily oral dose of $30 \mu \mathrm{l}$ of minocycline (Sigma-Aldrich; $50 \mathrm{mg} / \mathrm{ml}$ in distilled water; $n=10)$ or distilled water $(n=7)$ for $5 \mathrm{~d}$. Following $T$ pellet removal, birds were housed in ShD for $3 \mathrm{~d}$. On the third day of LDT withdrawal (LDW) and $2 \mathrm{~h}$ before tissue collection, all birds were injected with one dose of $\operatorname{BrdU}(50 \mathrm{mg} / \mathrm{ml})$ to label the proliferation of NPCs and their recent progeny in the VZ. As a control for off-target or basal effects of minocycline, another group of birds received oral administration of minocycline and a BrdU injection as described above but were maintained in LDT for the duration of the experiment $(n=4)$. Unfortunately, due to the required repeated handling of the birds, we were not able to obtain singing behavior in this study.

Blood draw and hormone analysis. Blood samples were obtained from all birds after they were killed to measure circulating $T$ concentrations. We drew $\sim 250 \mu \mathrm{l}$ of blood from the alar vein in the wing into heparinized collection tubes, immediately centrifuged the tubes, and stored the plasma at $-20^{\circ} \mathrm{C}$ until assay. Plasma T concentrations were measured using a Testosterone Enzyme Immunoassay kit (Enzo Life Sciences). Samples with undetectable levels of T $(n=11)$ were treated as having concentrations at the minimum detection $(0.03 \mathrm{ng} / \mathrm{ml}$ for $\mathrm{ShD}$ birds) or maximum detection (20.00 ng/ml for LDT birds) limit for statistical analyses. Intraassay and interassay coefficients of variation were 0.59 $41.25 \%$ and $10.00 \%$, respectively.

Tissue collection and processing. Five to $7 \mathrm{~h}$ after lights-on, birds were deeply anesthetized with isoflurane (4\%). Within $2 \mathrm{~min}$, brains were removed and bisected at the midline. One randomly chosen hemisphere was frozen on dry ice for histology and stored at $-80^{\circ} \mathrm{C}$ until cryosectioning. Each frozen brain was sectioned in the coronal plane at $40 \mu \mathrm{m}$ on a cryostat with each section thaw mounted serially. Every third slide was Niss stained with thionin, and the remaining slides were stored at $-80^{\circ} \mathrm{C}$ until immunolabeling. The other half of each brain was used for piloting a different experiment not included here; thus, all histologic measurements described below are reported as unilateral counts or densities. No significant effects of right versus left hemisphere were identified within experimental groups, and so all data were pooled for each experimental group.

Immunohistochemistry analyses. To confirm localization of LPS (Fig. 3A), we fixed slides of mounted tissue in $4 \%$ paraformaldehyde (PFA) and counterstained tissue with the nuclear marker Hoechst $33342(0.2 \mathrm{mg} / \mathrm{ml}$ in distilled $\mathrm{H}_{2} \mathrm{O}$ ) for $20 \mathrm{~min}$. Slides were rinsed in PBS and mounted with anti-fade mounting medium (1\% $\mathrm{n}$-propyl-gallate, $90 \%$ glycerol in PBS).

To visualize BrdU-labeled cells (Fig. 3B), mounted sections were fixed in $4 \%$ PFA, rinsed with PBS with $0.5 \%$ DMSO and 0.5\% Triton-X (PDTX; pH 7.4), dipped in distilled water, incubated with $2 \mathrm{~N} \mathrm{HCl}$ at $37^{\circ} \mathrm{C}$ for $30 \mathrm{~min}$, and rinsed with PDTX. After blocking in $5 \%$ heat-inactivated goat serum (Vector Laboratories) for $1 \mathrm{~h}$, slides were incubated serially with rat anti-BrdU (1:200; catalog \#MCA2060, BioRad) and Invitrogen mouse anti-HuC (1:100; Thermo Fisher Scientific) antibodies. HuC is a neuron-specific antigen expressed in both immature and fully differentiated neurons (Barami et al., 1995). Labeling was visualized with diaminobenzidine (DAB) staining following incubation with biotinylated goat anti-rat and anti-mouse IgG secondary antibodies (1:200; Vector Laboratories) and amplification with avidin-biotin peroxidase complex (ABC kit, Vector Laboratories). To 
A

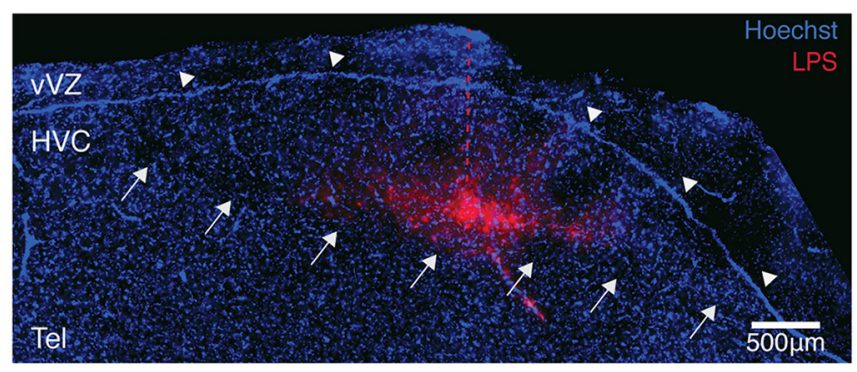

B

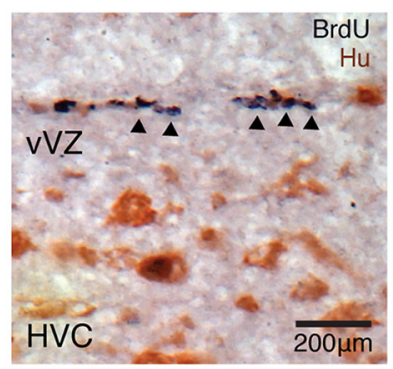

C

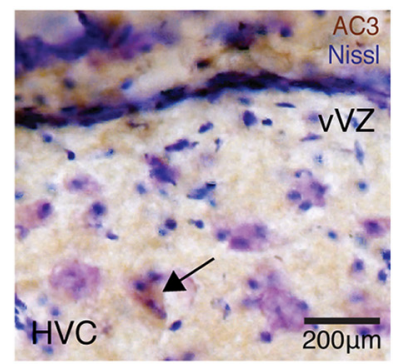

D

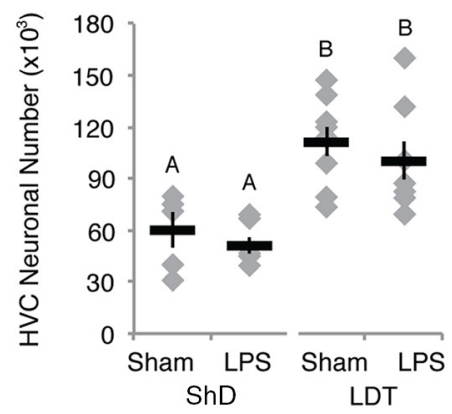

E

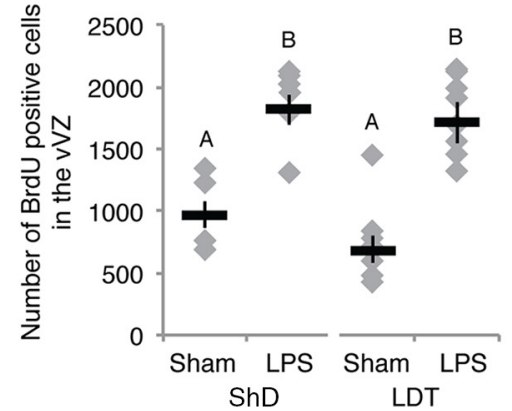

F

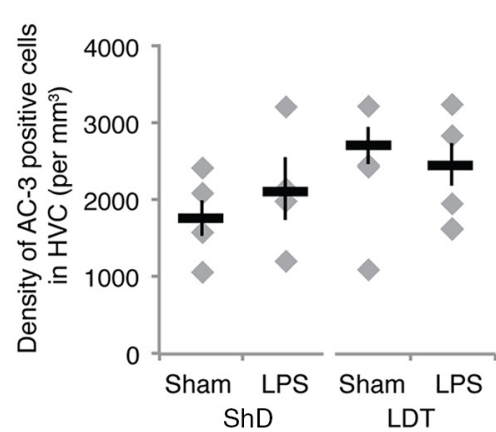

Figure 3. Local, acute inflammation induced a rapid increase in NPC proliferation independently of physiological condition (i.e., breeding or nonbreeding) and cell death. A, Image of Alexa Fluor-conjugated LPS localization within HVC 3 h after microinjection. LPS is shown in red; Hoechst 33342, a nuclear stain, is shown in blue. White arrows indicate the ventral boarder of HVC, white arrowheads indicate the VVZ, and the red dotted line indicates the injection needle track. Tel, Telencephalon. $\boldsymbol{B}$, BrdU labeling (dark purple, indicated by black arrowheads) in the vVZ, just dorsal to HVC. Tissue was colabeled with an antibody against the neuronal antigen HuC/D to provide histologic landmarks during analyses. $\boldsymbol{C}$, Cell death within HVC as indicated by AC-3-positive immunolabeling in brown, as indicated by the black arrow. Tissue is Nissl counterstained to identify the borders of HVC. D, Number of all HuC/ D-positive neurons (i.e., new plus mature) in one hemisphere of HVC across experimental and control groups. The HVC neuron number was consistently lower in nonbreeding than breeding conditions. LPS did not affect the total neuronal number in breeding or nonbreeding condition birds. $\boldsymbol{E}$, Number of BrdU-positive cells in the vVZ of experimental and control groups in breeding and nonbreeding conditions. LPS increased the numbers of new cells in VVZ equally in both breeding and nonbreeding condition birds. $\boldsymbol{F}$, The density of AC-3-positive cells did not differ between LPS-injected and control birds, or between long-term breeding and long-term nonbreeding conditions. $\boldsymbol{E}, \boldsymbol{F}$, Different letters above error bars indicate significant differences among groups, as determined with post hoc Tukey's test analyses (Table 1, ANOVA effects). All data are plotted as the mean \pm SEM (black), with data for each individual bird displayed as gray diamonds.

obtain a purple precipitate for the BrdU antigen, we used DAB-nickel stain $(0.05 \%$ DAB, $0.05 \%$ nickel ammonium sulfate, and $0.015 \% \mathrm{H}_{2} \mathrm{O}_{2}$ in PBS). BrdU-positive cells in the VVZ were counted from the hillock of the VZ medial to HVC, out to the most lateral extension of the vVZ in all sections that exhibited arching of the VZ (Scott and Lois, 2007; Larson et al., 2014).

Activated caspase-3 (AC-3) immunolabeling was used to identify cells undergoing apoptosis (Fig. 3C; Srinivasan et al., 1998). Sections were blocked with 5\% heat-inactivated goat serum, incubated with rabbit anti-AC-3 antibody (1:400; catalog \#13847, Abcam), and then incubated with biotinylated goat anti-rabbit lgG secondary antibody (1:200; Vector Laboratories; Larson et al., 2014). DAB staining was performed following amplification with the ABC kit (Vector Laboratories). Sections were lightly counterstained with thionin, a Nissl stain. AC-3-positive cells were counted from at least four HVC sections per bird using a previously described sampling protocol (Larson et al., 2014).
Microglia were detected with biotinylated Ricinus communis Agglutinin I (RCA-I; 1:250; catalog \#B-1085, Vector Laboratories; Mannoji et al., 1986) after 4\% PFA for $20 \mathrm{~min}, 15 \% \mathrm{MeOH}$ in PBS for $15 \mathrm{~min}$, PBS rinses, and $5 \%$ heat-inactivated goat serum for $1 \mathrm{~h}$. To visualize labeling, DAB-nickel staining was performed as above following amplification of the biotinylated lectin with the ABC Kit (Vector Laboratories). Neurons were labeled with the mouse anti-HuC antibody and detected with a biotinylated goat-anti-mouse antibody and DAB, as described above. To counterstain tissue, slides were briefly dipped in distilled water, incubated in methyl green $(0.5 \%$ ethyl violet in $0.1 \mathrm{~m}$ sodium acetate, $\mathrm{pH} 4.2$ ) at $60^{\circ} \mathrm{C}$ for $5 \mathrm{~min}$, and rinsed in distilled water until the runoff was clear. Microglia were quantified within the full extent of HVC based on morphologic characteristics previously described (Perez-Pouchoulen et al., 2015). Categories included the following: (1) resting or ramified microglia with three or more thin processes; (2) intermediate microglia 
A

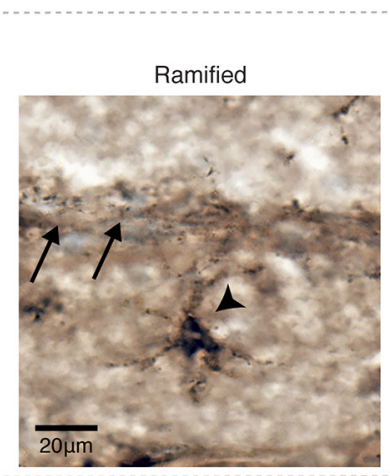

B

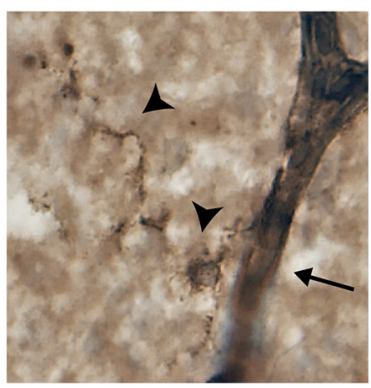

Total Active

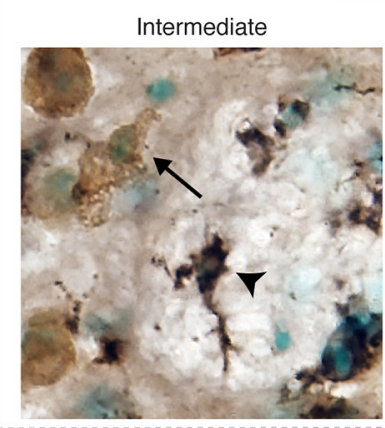

C

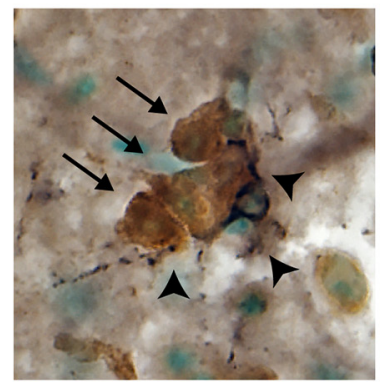

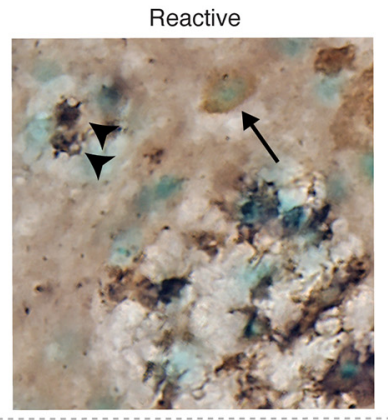

D

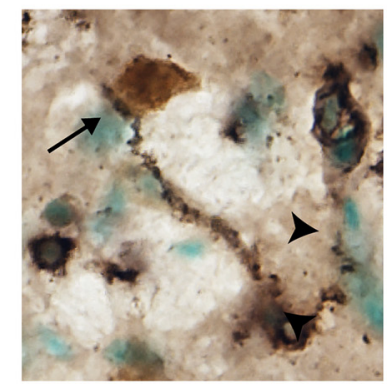

Figure 4. Representative images of microglia with different morphologies observed within HVC. A-D, Microglia are stained with RCA-I (black), and neurons are immunolabeled for neuronal antigen HuC/D (brown). Nuclei are counterstained with methyl green (green). A, Three morphologies of microglia quantified in HVC (within dotted box). Ramified microglia (arrowhead) in close proximity to the vVZ (arrows; farthest left image). Active microglia including intermediate microglia (arrowhead; middle image) and reactive microglia (arrowhead; farthest right image) with commingling with neurons (arrows). B, Ramified microglia (arrowhead) in HVC contacting the vasculature (arrow). C, Ramified microglia (arrowhead) with processes intermingling with neuronal soma (arrows). $\boldsymbol{D}$, Microglia with processes in contact with neuronal soma (arrow) and a non-neuronal cell (arrowhead).

with one or two thick processes; and (3) reactive microglia with stout, thick processes or round/amoeboid morphology (Fig. 4).

All immunohistochemistry was performed in batches of up to 28 slides with tissue from randomly chosen birds. Each batch included one positive and one negative control slide, which, if it failed, forced the removal of the entire batch from subsequent quantification. Thus, not all measurements include data from all experimental birds. All measurements were made blind to experimental group. All cell counts were adjusted using the Konigsmark formula number four for cell splitting (Konigsmark, 1970).

Morphometric measurements. The volume of HVC was determined by tracing the borders of the nuclei identified in thionin-stained tissue onto paper and quantifying the area of the digitally scanned tracing using ImageJ Software (version 1.46; NIH; http://rsb.info.nih.gov/ij/). Total volumes were calculated from areas of the tracings using the formula for a truncated cone (Tramontin et al., 1998). All HuC-positive neurons that fell within an ocular grid $\left(0.0156 \mathrm{~mm}^{2}\right.$ at $\left.400 \times\right)$ randomly positioned within every section through the full extent of HVC were counted to calculate HVC neuronal density. Neuronal number was obtained by multiplying neuronal density for each bird by that bird's unilateral HVC volume.

Statistical analyses. Comparisons of LPS were made with two-way ANOVAs with breeding condition and treatment as the factor, whereas minocycline comparisons were made with one-way ANOVA with treatment as the factor. For microglia cell types (ramified, intermediate, and reactive), multivariate ANOVAs (MANOVAs) were performed with bird, breeding condition, and treatment as factors for the LPS study, and bird and experimental conditions as the factor for the minocycline study. For both datasets, the sphericity tests reported probabilities of $<0.05$ (0.0002 and 0.0185, respectively). Student's $t$ tests were performed to compare data across breeding and nonbreeding, and regressed condition with data from minocycline-treated and water-treated birds in LDW condition pooled. Post hoc Tukey's tests were performed only if the overall main effect of the ANOVA was significant. Results of the post hoc Tukey's test analyses are denoted by superscript letters in Tables 1 and 2 and capitalized letters in graphs. All statistical analyses were made using JMP version 8.0.1 (SAS) with an $\alpha$ level of 0.05. All data are presented as the mean \pm SEM.

\section{Results}

\section{Acute HVC inflammation rapidly increases VVZ proliferation regardless of hormonal state}

Given that HVC neuronal cell death induces reactive neurogenesis (Larson et al., 2014) and that neuronal death initiates inflammatory responses in mammals (Ekdahl, 2012; Ritzel et al., 2013) and fish (Kizil et al., 
Table 1: Sex steroid levels, morphometrics, and cellular changes with induction of inflammation

\begin{tabular}{|c|c|c|c|c|c|c|c|c|}
\hline & \multicolumn{2}{|c|}{ ShD } & \multicolumn{2}{|c|}{ LDT } & \multirow[b]{2}{*}{$\begin{array}{l}\text { ANOVA main effect } \\
\text { (two-way) }\end{array}$} & & \multirow[b]{2}{*}{ Condition (ShD vs LDT) } & \multirow[b]{2}{*}{ Injection * Condition } \\
\hline & $\begin{array}{l}\text { Sham } \\
(n=5)\end{array}$ & $\begin{array}{l}\text { LPS } \\
(n=6)\end{array}$ & $\begin{array}{l}\text { Sham } \\
(n=9)\end{array}$ & $\begin{array}{l}\text { LPS } \\
(n=9)\end{array}$ & & $\begin{array}{l}\text { Injection type } \\
\text { (Sham vs LPS) }\end{array}$ & & \\
\hline \multicolumn{9}{|l|}{ Testosterone } \\
\hline $\begin{array}{l}\text { Plasma levels (ng/ml) } \\
\text { HVC }\end{array}$ & $0.07 \pm 0.03^{a}$ & $0.08 \pm 0.02^{\mathrm{a}}$ & $15.80 \pm 1.69^{\mathrm{b}}$ & $17.70 \pm 1.65^{\mathrm{b}}$ & $F_{(3,20)}=31.8914 ; p<0.0001$ & $F=0.2986 ; p=0.5908$ & $F=990.7318 ; p<0.0001$ & $F=0.2920 ; p=0.5949$ \\
\hline $\begin{array}{l}\text { Unilateral } \\
\text { volume }\left(\mathrm{mm}^{3}\right)\end{array}$ & $0.42 \pm 0.05^{a}$ & $0.41 \pm 0.04^{\mathrm{a}}$ & $0.80 \pm 0.05^{\mathrm{b}}$ & $0.75 \pm 0.06^{\mathrm{b}}$ & $F_{(3,24)}=10.6481 ; p<0.0001$ & $F=0.3873 ; p=0.5396$ & $F=30.5611 ; p<0.0001$ & $F=0.2033 ; p<0.0001$ \\
\hline $\begin{array}{l}\text { Neuron density } \\
\left(\times 10^{3} / \mathrm{mm}^{3}\right)\end{array}$ & $130 \pm 5^{\mathrm{a}, \mathrm{b}}$ & $117 \pm 4^{\mathrm{a}}$ & $129 \pm 3^{b}$ & $128 \pm 4^{b}$ & $F_{(3,25)}=6.8570 ; p=0.0016$ & $F=1.8998 ; p=0.1803$ & $F=16.3837 ; p=0.0004$ & $F=1.9168 ; p=0.1784$ \\
\hline $\begin{array}{l}\text { Unilateral neuron } \\
\text { number }\left(\times 10^{3}\right)\end{array}$ & $60 \pm 10^{\mathrm{a}}$ & $51 \pm 5^{\mathrm{a}}$ & $111 \pm 9^{b}$ & $100 \pm 11^{b}$ & $F_{(3,24)}=5.3377 ; p=0.0058$ & $F=0.0773 ; p=0.7834$ & $F=15.1049 ; p=0.0007$ & $F=0.5399 ; p=0.4696$ \\
\hline $\begin{array}{l}\text { AC-3 cell density } \\
\left(\text { per } \mathrm{mm}^{3}\right)\end{array}$ & $1747 \pm 230$ & $2132 \pm 411$ & $2696 \pm 241$ & $2445 \pm 271$ & $F_{(3,21)}=2.0696 ; p=0.1349$ & $F=0.0432 ; p=0.8373$ & $F=4.4773 ; p=0.0465$ & $F=1.1176 ; p=0.3025$ \\
\hline $\begin{array}{l}\text { Unilateral AC-3 } \\
\text { cell number }\end{array}$ & $829 \pm 200^{a}$ & $946 \pm 245^{a}$ & $2328 \pm 292^{b}$ & $2060 \pm 360^{a, b}$ & $F_{(3,21)}=5.9919 ; p=0.0041$ & $F=0.1334 ; p=0.7186$ & $F=16.1711 ; p=0.0006$ & $F=0.4803 ; p=0.4803$ \\
\hline \multicolumn{9}{|l|}{ Microglia in HVC } \\
\hline Ramified & $295 \pm 86$ & $231 \pm 29$ & $479 \pm 38$ & $451 \pm 73$ & $F_{(3,18)}=2.6917 ; p=0.0770$ & $F=2.1850 ; p=0.1566$ & $F=5.4407 ; p=0.0315$ & $F=1.0983 ; p=0.3085$ \\
\hline Intermediate & $85 \pm 30$ & $128 \pm 11$ & $142 \pm 23$ & $139 \pm 40$ & $F_{(3,18)}=0.5415 ; p=0.660$ & $F=0.3760 ; p=0.5474$ & $F=1.1190 ; p=0.3041$ & $F=0.2635 ; p=0.6139$ \\
\hline Reactive & $32 \pm 12$ & $43 \pm 7$ & $48 \pm 10$ & $51 \pm 11$ & $F_{(3,18)}=0.4788 ; p=0.7010$ & $F=0.4027 ; p=0.5337$ & $F=1.0125 ; p=0.3276$ & $F=0.0982 ; p=0.7576$ \\
\hline Total active & $129 \pm 41$ & $156 \pm 12$ & $190 \pm 33$ & $190 \pm 49$ & $F_{(3,18)}=0.4510 ; p=0.7197$ & $F=0.0976 ; p=0.7583$ & $F=1.1961 ; p=0.2885$ & $F=0.1018 ; p=0.7533$ \\
\hline \multicolumn{9}{|c|}{ ( } \\
\hline $\begin{array}{l}\text { Unilateral BrdU- } \\
\text { positive cel } \\
\text { number }\end{array}$ & $971 \pm 164^{a}$ & $1819 \pm 123^{b}$ & $690 \pm 113^{a}$ & $1712 \pm 106^{\mathrm{b}}$ & $\begin{array}{l}F_{(3,22)}=22.0745 ; p \\
\quad<0.0001\end{array}$ & $F=54.4770 ; p<0.0001$ & $F=2.394 ; p=0.1412$ & $F=0.4709 ; p=0.4997$ \\
\hline \multicolumn{9}{|l|}{ Age } \\
\hline $\begin{array}{l}\text { Minimum age } \\
\text { (month) }\end{array}$ & $21 \pm 2$ & $19 \pm 3$ & $20 \pm 2$ & $17 \pm 2$ & $F_{(3,25)}=0.3227 ; p=0.8089$ & $F=0.5843, p=0.4518$ & $F=0.2273, p=0.6377$ & $F=0.0493, p=0.8262$ \\
\hline
\end{tabular}

All values are the mean \pm SEM. Superscript letters denote significant differences across treatment groups with post hoc Tukey's test, only if the main effect of ANOVA was significant.

2012; Kyritsis et al., 2012), we hypothesized that inflammation following HVC neuronal death regulates reactive NPC proliferation in the VVZ. To experimentally dissociate neuronal death in HVC from any putative inflammatory response, we induced local inflammation response by injecting a bacterial coat protein, LPS (1 $\mu$; Fig. 2, dosage titration; Andersson et al., 1992; Buttini et al., 1996) into HVC of birds exposed to photoperiod and hormonal

Table 2: Sex steroid levels, morphometrics, and cellular changes with inhibition of inflammation

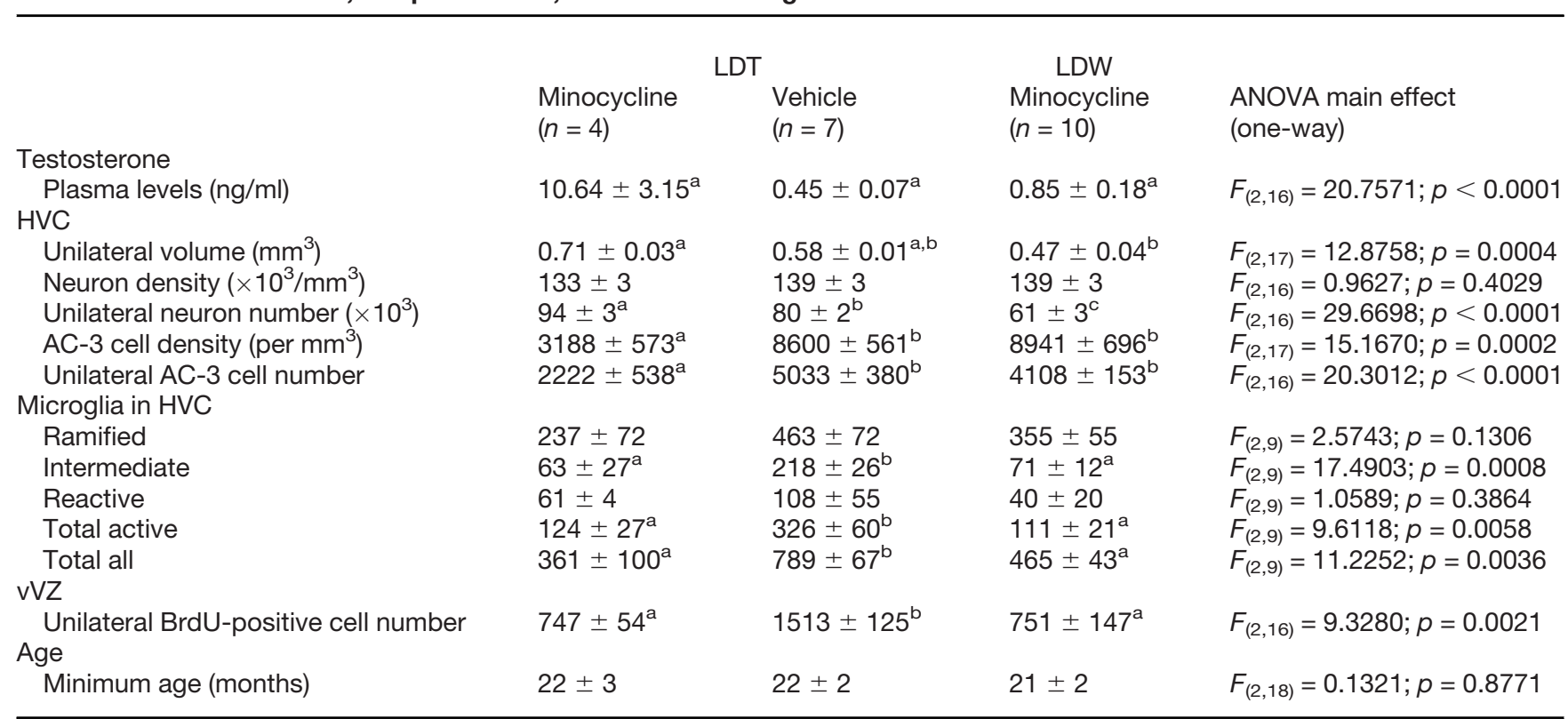

All values are the mean \pm SEM. Superscript letters denote significant differences across treatment groups with post hoc Tukey's test, only if the main effect of ANOVA was significant. 
A

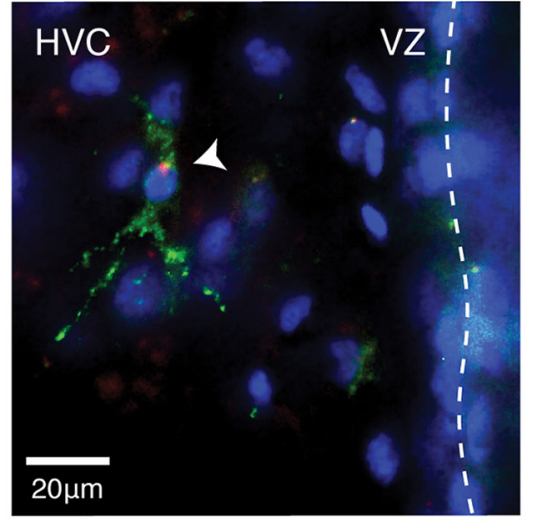

B

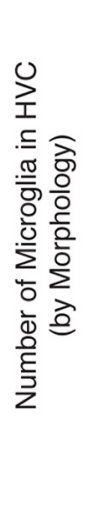

Ramified

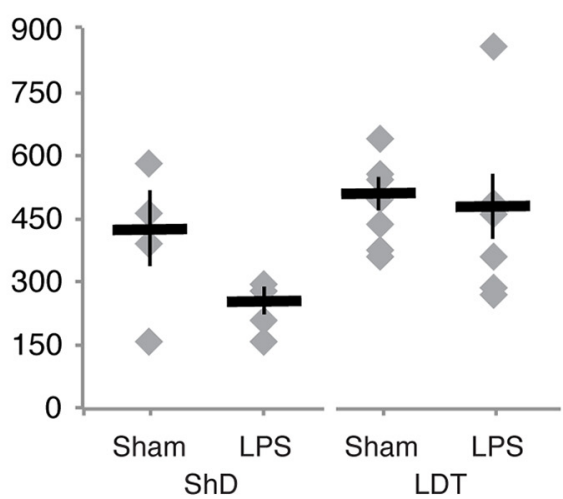

Total Active

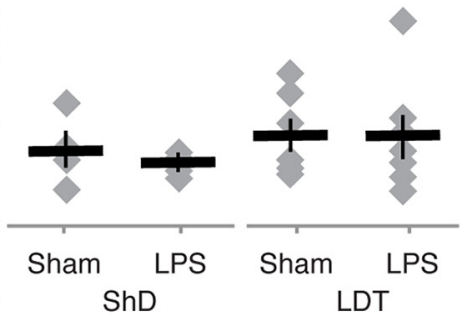

Figure 5. Microglial response to microinjection LPS into HVC. A, A microglial cell labeled with RCA-I (green) in HVC near the vVZ (dotted line). The presence of fluorophore-conjugated LPS (red) puncta within the cell body of the microglia is suggestive of endocytosis of the LPS by microglia. Cell nuclei stained with Hoechst 33342 are shown in blue. $\boldsymbol{B}$, Number of RCA-I-labeled microglia as distinguished by morphology in HVC of one hemisphere (see also Table 1).

manipulations to induce a breeding (i.e., LDT) or nonbreeding-like (i.e., ShD) physiological condition (see Materials and Methods). We confirmed discrete localization of injected Alexa Fluor 568-conjugated LPS within HVC (Fig. 3A). We also confirmed that hormonal and light manipulations induced physiological and morphologic states typical of breeding and nonbreeding conditions. Consistent with previous reports (Smith et al., 1997; Tramontin et al., 2000), systemic testosterone (T) plasma levels, HVC volume, and HVC neuronal number were all significantly higher in breeding condition compared with nonbreeding condition (Student's $t$ test, $p<0.001$, each; Fig. 3D, Table 1 for data and statistics).

To test whether local acute inflammation could rapidly elicit NPC proliferation in the VVZ, we quantified BrdU incorporation within proliferating NPCs and their recent progeny over $2 \mathrm{~h}$, beginning $1 \mathrm{~h}$ after LPS or sham injections in HVC (Fig. 3B,E). Moreover, because estrogen, a metabolite of $T$, modulates neuroinflammatory responses and generally promotes neuroprotection (for review, see Larson, 2018), we compared the effects of LPS-induced inflammation in birds maintained in both breeding (LDT $28 \mathrm{~d}$ ) and nonbreeding (ShD) conditions. In stable, long-term nonbreeding condition birds, the number of BrdU-positive cells in the vVZ was significantly higher following LPS injection compared with sham injections (post hoc Tukey's test, $p=0.0018$; Fig. $3 E$, Table 1, data and ANOVA effects). Likewise, in the stable breeding condition, LPS microinjection increased the number of BrdU-positive cells in the vVZ compared with sham injection (post hoc Tukey's test, $p<0.0001$; Table 1, Fig. 3E). Contrary to prediction, the number of BrdU-positive cells in the VVZ did not differ between stable nonbreeding (i.e., low T) and breeding (high T) conditions following LPS injection (post hoc Tukey's test, $p=0.9196$ ) or sham injection (post hoc Tukey's test, $p=0.4687$; Table 1, Fig. 3E). Together, these data indicate that LPS rapidly (within $3 \mathrm{~h}$ ) increases NPC proliferation under both breeding and nonbreeding conditions, and this inflammatory-mediated proliferation of NPCs was not influenced by long-term elevation of circulating sex steroids.

To exclude the possibility that differential VVZ proliferation resulted from nonspecific cell death induced by LPS (Fig. 2; Semmler et al., 2005) or possible differences in HVC apoptosis under stable breeding and nonbreeding conditions (Kirn et al., 1994; but see Larson et al., 2014), we quantified apoptosis in HVC by immunohistochemistry for AC-3 (Fig. 3C,F; Larson et al., 2014). We found no differences in the density of AC-3-positive cells between sham-injected and LPS-injected groups (Table 1, Fig. 3F, data and statistics). Moreover, we found no significant difference in the density of apoptotic cells in HVC between long-term breeding and nonbreeding conditions (Table 1 , Fig. 3F). These data confirm that differences in vVZ proliferation were not due to nonspecific changes associated with cell death or season, but rather resulted from a rapid response to local LPS microinjection.

\section{Local LPS injection does not rapidly induce microglia change to activated morphology}

Given that microglia are a major cell type orchestrating inflammatory responses within the CNS following endotoxin-induced and injury-induced neuronal loss, we asked whether microglia mediated the effects of LPS in HVC on reactive neurogenesis. Following Alexa Fluor 568-conjugated LPS injection into HVC, we identified microglia present in HVC that colabeled with puncta of LPS (Fig. $5 A)$. The appearance of LPS puncta in close proximity to the soma of microglia within HVC suggested that microglia were endocytosing and responding to the LPS in the avian brain. Quantification of all RCA-1-labeled microglia within HVC following LPS stimulation revealed no significant differences in the number of microglia, regardless of morphology, between LPS -injected and sham-injected groups (data and ANOVA are in Table 1, Fig. 5B); the MANOVA for effects of experimental conditions on microglia morphology types was not significant (between subjects: $F=0.4181, p=0.0915$; within subjects: Wilks' $\lambda$, 
A

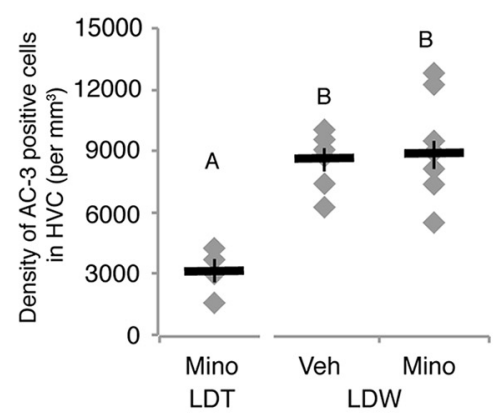

B

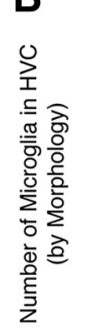

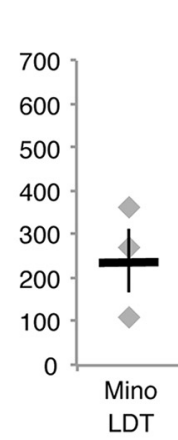

Ramified
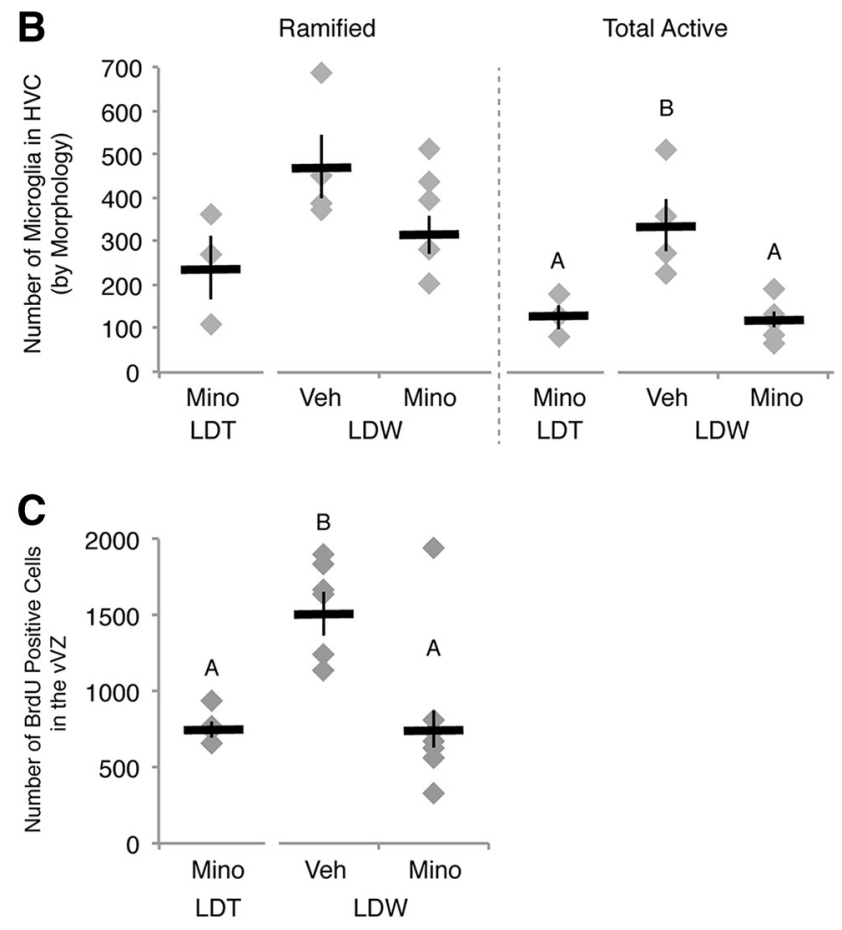

Figure 6. Systemic administration of minocycline (Mino) prevented natural, reactive NPC proliferation following HVC neuronal loss. $\boldsymbol{A}$, Density of apoptotic cells in HVC. The number of dying cells in HVC as shown by AC-3-positive labeling increased in birds transitioned from breeding to nonbreeding conditions and was not altered by minocycline administration. $\boldsymbol{B}$, Number of RCA-I-labeled microglia as distinguished by morphology in HVC of one hemisphere (see also Fig. 4, Table 2). The combined number of microglia with activated morphology (intermediate and reactive) was upregulated during regression [i.e., LDW with vehicle (Veh) administration (LDW-V)] when compared with breeding condition birds [i.e., LDT with vehicle (LDTV)]. Minocycline reduced the activation of microglia during periods of neuronal loss in HVC in LDW birds (i.e., LDW-M). $\boldsymbol{C}$, The number of BrdU-positive cells in the VVZ was greater in vehicle control birds transitioned from LDT to ShD, as previously reported (Larson et al., 2014), than birds maintained in LDT. Administration of minocycline prevented reactive NPC proliferation in the VVZ during active HVC regression, suggesting that inflammation is necessary for reactive neurogenesis. $\boldsymbol{A}-\boldsymbol{C}$, Letters above bars indicate significant differences among groups (ANOVA, post hoc Tukey's test). Different letters above error bars indicate significant differences among groups as determined with post hoc Tukey's test analyses (but see Table 2 for $p=0.2193$ ). Our data indicate that neither microglia activation (as determined here by morphology rather than microglial behavior) nor proliferation occurred within $3 \mathrm{~h}$ of LPS administration. Thus, our data suggest that if microglia are involved in mediating the initial phases of an LPSinduced inflammatory response (as would be predicted; Buttini et al., 1996; Hauss-Wegrzyniak et al., 1998), then microglia could induce NPC proliferation without a change in morphology. Alternatively, the effects of local inflammation could be mediated, in part or entirely, through a yet undetermined cell type such as astroglia. We also found no significant differences in numbers of microglia, regardless of microglial morphology or LPS treatment, between breeding and nonbreeding conditions, suggesting that chronic elevation of sex steroids does not alter baseline microglia numbers or response to LPS.

\section{Microglia activation is necessary for reactive neurogenesis following seasonally induced neurodegeneration}

The impact of inflammation on NPC behavior in the adult brain under non-injury-induced neural degenerative conditions is unknown. Thus, we tested whether or not inflammation is necessary for reactive neurogenesis during the transition from breeding to nonbreeding conditions, when there is extensive death of mature neurons (Fig. 1A; Larson et al., 2014). We inhibited putative neural inflammation with oral doses of anti-inflammatory minocyclinea selective inhibitor of microglial polarization from the ramified state (Kobayashi et al., 2013)-throughout the duration of HVC regression. We first confirmed that transition from breeding to nonbreeding conditions (i.e., LDW) induced HVC regression. Consistent with previous reports (Thompson et al., 2007; Larson et al., 2014), we found that transition to LDW decreased plasma T levels (Student's $t$ test, $p<0.0001$; Table 2 for data), HVC volume (Student's $t$ test, $p=0.0016$; Table 2), and HVC neuronal number (Student's $t$ test, $p=0.0117$; Table 2) compared with values from breeding condition birds. Furthermore, as expected (Larson et al., 2014), the density and total number of apoptotic neurons were elevated in HVC of all birds transitioned to nonbreeding condition (i.e., minocycline-treated and vehicle-treated birds), compared with birds maintained in breeding condition (Student's $t$ test, $p<0.001$ and $p=0.0003$, for AC-3-positive cell density and total number, respectively; Fig. $6 A$, Table 2). These data confirm that photoperiod and $T$ manipulations reproduced seasonallike neuronal death and regression of HVC regression.

We also confirmed that minocycline prevented an anticipated upregulation of microglial activation and possible microglial proliferation with increased cell death in HVC. We found that minocycline prevented an increase in the total number of microglia and the number of activated microglia when compared with vehicle controls with oneway ANOVA post hoc Tukey's test, $p=0.0115$ and

\section{continued}

ANOVA effects). All data are plotted as the mean \pm SEM (black), with individual data values displayed as gray diamonds. 
$p=0.0069$, respectively; Fig. $6 B$, Table 2 for data and main effect of ANOVA). MANOVA for the three microglia morphology types further supported ANOVA results with experimental conditions having a significant effect on microglia numbers (between subjects: $F=2.4945, p=0.0036$; within subjects: Wilk's $\lambda, p=0.3857$ ). Moreover, minocycline administration during HVC regression (LDW) reduced the total number of microglia and the number of activated microglia to levels observed in HVC of birds in stable breeding condition (post hoc Tukey's test, $p=0.5266$ and $p=0.9747$, respectively; Fig. $6 B$, Table 2). The lower number of activated microglia with minocycline administration compared with vehicle was primarily driven by a decrease in the number of microglia with intermediate morphology (post hoc Tukey's test, $p=0.0013$; Table 2). These data confirm that minocycline inhibits microglia activation in HVC of birds and suggests that any effects of minocycline treatment on NPC proliferation would be mediated, at least in part, through the activation of microglia.

We tested the necessity of microglial activation during $H V C$ regression for subsequent reactive neurogenesis in the nearby VVZ and found that the number of BrdU-positive cells in the vVZ was reduced in minocycline-administered birds compared with birds receiving water vehicle (post hoc Tukey's test, $p=0.0026$; Table 2, Fig. $6 C$ ). The density and total number of apoptotic cells in HVC were not significantly different between minocycline-treated and vehicle-treated birds (post hoc Tukey's test, $p=0.8860$ and $p=0.1727$, respectively; Table 2, Fig. 6A). Moreover, the total number of neurons in HVC of birds transitioned to nonbreeding conditions decreased equivalently in minocycline-treated and vehicle-treated birds (post hoc Tukey's test, $p=0.3279$; Table 2). Together, these data demonstrate that inflammation is necessary for the reactive neurogenesis in VVZ induced by the death of mature HVC neurons, but that inflammation itself does not reciprocally contribute to secondary HVC neuronal loss during natural regression.

To rule out possible systemic effects of minocycline (Strahan et al., 2017), we administered minocycline to an additional group of birds maintained in long-term breeding conditions (i.e., $28 \mathrm{~d}$ ). BrdU-positive cell numbers in the vVZ of minocycline-LDT-treated birds did not differ from those maintained in LDT for $28 \mathrm{~d}$ without any treatment (data from Larson et al., 2014), or sham injected while in LDT (one-way ANOVA, $\left.F_{(2,14)}=0.2696, p=0.7695\right)$. Moreover, the number of HVC neurons labeled with the neuronal marker HuC/D did not differ between these treatment groups (one-way ANOVA, $\left.F_{(2,14)}=1.0515, p=0.3755\right)$. The number of apoptotic cells in HVC also did not differ between minocyclinetreated and vehicle-treated LDT birds (Student's $t$ test, $p=0.3616$ ). Effects of minocycline on HVC cell death across studies were not tested because the AC-3 antibody used for quantification of AC-3-positive cells in the 28D LDT birds from the prior study (Larson et al., 2014) was discontinued by the vendor (Tables 1, 2, AC-3 cell counts of current study with alternative AC-3 antibody).

\section{Discussion}

How classically defined "inflammatory cells" contribute to the establishment and maintenance of cell populations, tissue structure, and ultimately organismal behavior is an important, yet understudied, question. The seasonally plastic avian song circuit provides a unique model for identifying the cellular and molecular mechanisms underlying not only normal neuronal turnover, but also changes associated with non-injury-induced neural degeneration. Here, we demonstrate that acute inflammation induced locally within HVC, even in the absence of cell death, is sufficient to promote NPC proliferation in the VVZ, adjacent to but outside HVC. We also show that inflammation is necessary for the increase in NPC proliferation following seasonally induced HVC neuronal loss, and that microglia are very likely to be involved. Our work is the first to suggest that neuroinflammatory processes modulate NPC proliferation during natural reactive neurogenesis, and provides a tractable model for future investigations of the cell types and mechanisms linking natural neuronal apoptosis, compensatory neurogenesis, and return to homeostasis.

\section{Local neuroinflammation drives VVZ NPC proliferation}

We found that acute LPS exposure within HVC rapidly increased NPC proliferation in the vVZ, which supplies HVC with new neurons (Scott and Lois, 2007). The effects of LPS microinjection within HVC on NPC proliferation did not result from local cell death, which is, itself, known to alter NPC proliferation (Lee et al., 2005; Semmler et al., 2005). The LPS-dependent increase in NPC proliferation that we observed is consistent with some, but not all, reports in mammals. In rats, the injection of $15 \mu \mathrm{g}$ of LPS into the striatum increased neurogenesis after 2 weeks to an extent comparable to that induced by middle cerebral artery occlusion (Chapman et al., 2015). We found an increase in NPC proliferation $3 \mathrm{~h}$ after the injection of $1 \mu \mathrm{g}$ of LPS that was similar to the increase induced by cell death during HVC regression (Larson et al., 2014). Our results, however, are inconsistent with reports of decreased proliferation 5-24 h after intraperitoneal LPS administration in rodents (Vallières et al., 2002; Fujioka and Akema, 2010) and reports of decreased neurogenesis $28 \mathrm{~d}$ after intraperitoneal infusion of LPS in rodents (Ekdahl et al., 2003). The contradictions in proliferative response between these studies and our studies likely reflect differences in the injections sites of LPS, the time course of LPS exposure, possible types of inflammatory responses mounted, the model organism tested, or some combination of these factors (Ekdahl et al., 2003; Semmler et al., 2005; Zhao et al., 2019). Systemic inflammation induced with intraperitoneal LPS impacts proliferation and neurogenesis though a systemic cytotoxic proinflammatory response (Kohman and Rhodes, 2013). Alternatively, LPS injection directly into the brain may promote an anticytotoxic, proneurogenic response through a Toll-like receptor 4-mediated enhancement of interferon- $\beta$ (Jacobs and Ignarro, 2001) and suppression of proinflammatory nuclear factor $-\kappa \mathrm{B}$ activity (Vartanian et al., 2011), which together reduce inflammatory factor secretion and inflammatory cell infiltration (Kuo et al., 2016).

We also tested the role of inflammation as the signal of HVC cell death status to the VVZ NPCs in the otherwise healthy adult brain. We found that the anti-inflammatory 
drug minocycline prevented natural reactive neurogenesis on rapid HVC regression, indicating that inflammation is necessary for HVC apoptosis to drive increased NPC proliferation. Our findings are consistent with previous reports that microglial activation is necessary for reactive neurogenesis following an ischemic event (Kim et al., 2009), but also highlight a novel role for inflammatory glia in modulating NPC behavior following normally occurring neuronal loss in the otherwise healthy adult brain.

\section{Interaction between breeding condition physiology and neuroinflammation}

Not only do activity, stress, and other physiological cues affect the immunogenicity of an apoptotic cell, but these factors similarly act directly on the inflammatory cells to alter their behavior. For example, following mechanical injury to the zebra finch telencephalon, activated astroglia initially promote a proinflammatory-like response through expression of the cytokines interleukin- $1 \beta$ and interleukin6 increases (Duncan and Saldanha, 2011), but subsequently "switch" to a more neuroprotective response by 20 $h$ through increased expression of aromatase, the enzyme that facilitates estradiol synthesis from $T$ (Duncan and Saldanha, 2011). Likewise, peripheral LPS administration in zebra finches increases transcription of aromatase in the telencephalon by $24 \mathrm{~h}$ postinjection (Pedersen et al., 2017b). This increase in LPS-induced aromatase expression is reduced with central administration of the anti-inflammatory drug indomethacin (Pedersen et al., 2017a). In mammals, both systemic and glial-derived elevations of estradiol reduce LPS-induced proinflammatory cytokine production by microglia (Vegeto et al., 2001) and astroglia (Loram et al., 2012). Thus, we had anticipated that elevated systemic $T$ would attenuate microglial activation and potentiate a proneurogenic response. Nevertheless, we found no interaction effects between sex steroid levels and minocycline or LPS administration on microglia number or NPC proliferation. Our results are likely due to the longterm, rather than acute, elevation of $\mathrm{T}$ and the localization of endotoxin stimulation. Together, these data suggest that inflammatory cell responses vary depending on the homeostatic state of the immediate environment.

\section{Immunogenic apoptosis occurs in HVC following natural regression}

We show a significant elevation in the number of activated microglia corresponding to increased apoptosis induced in HVC by the seasonal decrease of plasma T levels. Treating birds with the anti-inflammatory agent minocycline, however, did not reduce the number of neurons or apoptotic cells in HVC. In contrast with secondary cell death caused by activated microglia following ischemia (Tobin et al., 2014), our observation suggests that total neuronal loss in HVC during transition from breeding to nonbreeding conditions is not compounded by microglial involvement in the healthy adult avian brain. The general involvement of microglia following an increase in activated caspase-3-positive cell number in HVC might initially seem to conflict with findings that caspase-3-mediated apoptosis is typically nonimmunogenic (Fink and Cookson, 2005). Yet, caspase-3 activation is likely not the sole caspase involved in HVC seasonal neuronal loss: inhibition of caspases 1, 2, and 9, in addition to caspase-3, is necessary to prevent cell death during HVC regression and subsequent reactive neurogenesis (Thompson and Brenowitz, 2008; Larson et al., 2014). Thus, seasonally induced neuronal loss in HVC is likely not entirely mediated by caspase-3 signaling, and other caspases might be responsible for the immunogenic activation of microglia and resulting reactive neurogenesis.

\section{Cellular mediators of the local inflammatory response}

At first glance, our finding that LPS did not induce morphologic hallmarks of microglial activation might suggest that microglia do not contribute to the inflammatory-mediated increase of NPC proliferation. Nevertheless, given that microglial retraction of processes begins at $3 \mathrm{~h}$ and peaks at $\sim 8 \mathrm{~h}$ following peripheral LPS administration (Buttini et al., 1996), and that microglia can secrete cytokines in their "resting" or ramified state (for review, see Cherry et al., 2014), it may not be surprising that we did not observe a significant increase in the number of activated microglia $3 \mathrm{~h}$ after LPS injection into HVC. Although microglia are the dominant immunogenic cells within the brain and are well documented to respond robustly to LPS (Buttini et al., 1996; Hauss-Wegrzyniak et al., 1998), astrocytes can also become reactive and exhibit immunelike responses following neural insults including LPS stimulation (Wu et al., 1998). Our data support a model in which local inflammation stimulates NPC proliferation, though we cannot yet definitively assign these functions to one or the other cell type. Development of new reagents and tools for the avian system should permit such assessment in future efforts.

\section{Role of local inflammatory cells in homeostasis}

The impact of inflammation on cell behavior and tissue integrity has been examined primarily within the context of response to injury or endotoxin-induced insults. Yet, classically defined immune cells have roles beyond immune responses: macrophages, and by extension microglia, can act outside their classic inflammatory roles to regulate metabolism, vascularization, fluid balance, and development of tissue pattern (Wynn et al., 2013). For example, in tissues with underlying branching morphology, such as lung, kidney, mammary gland, and neural tissues, macrophages regulate patterning through the deposition of the surrounding collagen matrix and vasculature (for review, see Wood and Martin, 2017). Macrophages also provide a signaling relay between pigment cell types during larval-to-adult repatterning of the zebrafish pigment pattern (Eom and Parichy, 2017). Likewise, we found that the activation of local inflammatory cells promotes the previously described repatterning of HVC cytoarchitecture to the nonbreeding state through the modulation of NPC proliferation following natural neuronal loss in the adult avian forebrain (Larson et al., 2014). Our results are additionally concordant with the observation of microglia 
behavior during the development of the rat brain (Shigemoto-Mogami et al., 2014) in which activated microglia accumulate in the subventricular zone-a forebrain neurogenic niche in the mammalian brain-and secrete proinflammatory cytokines that stimulate early postnatal neurogenesis (Shigemoto-Mogami et al., 2014). Together, our findings support the expanding appreciation for roles of classically defined inflammatory cells in patterning and re-establishment of homeostasis after natural perturbation of neural tissue structure. This emerging role of inflammatory cells in maintaining neural homeostasis highlights the need for the field to shift from discussing the roles of glia and neural macrophages in overly general terms of neuroinflammation toward reference to the specific signaling mechanisms and behaviors of these cells.

\section{References}

Andersson PB, Perry VH, Gordon S (1992) The acute inflammatory response to lipopolysaccharide in CNS parenchyma differs from that in other body tissues. Neuroscience 48:169-186.

Barami K, Iversen K, Furneaux H, Goldman SA (1995) Hu protein as an early marker of neuronal phenotypic differentiation by subependymal zone cells of the adult songbird forebrain. $J$ Neurobiol 28:82-101.

Buttini M, Limonta S, Boddeke HW (1996) Peripheral administration of lipopolysaccharide induces activation of microglial cells in rat brain. Neurochem Int 29:25-35.

Chapman KZ, Ge R, Monni E, Tatarishvili J, Ahlenius H, Arvidsson A, Ekdahl CT, Lindvall O, Kokaia Z (2015) Inflammation without neuronal death triggers striatal neurogenesis comparable to stroke. Neurobiol Dis 83:1-15.

Cherry JD, Olschowka JA, O'Banion MK (2014) Are "resting" microglia more "m2"? Front Immunol 5:594.

DeVoogd T, Nottebohm F (1981) Gonadal hormones induce dendritic growth in the adult avian brain. Science 214:202-204.

Duncan KA, Saldanha CJ (2011) Neuroinflammation induces glial aromatase expression in the uninjured songbird brain. $J$ Neuroinflammation 8:81.

Ekdahl CT (2012) Microglial activation - tuning and pruning adult neurogenesis. Front Pharmacol 3:41.

Ekdahl CT, Claasen JH, Bonde S, Kokaia Z, Lindvall O (2003) Inflammation is detrimental for neurogenesis in adult brain. Proc Natl Acad Sci U S A 100:13632-13637.

Eom DS, Parichy DM (2017) A macrophage relay for long-distance signaling during postembryonic tissue remodeling. Science 355:1317-1320.

Fink SL, Cookson BT (2005) Apoptosis, pyroptosis, and necrosis: mechanistic description of dead and dying eukaryotic cells. Infect Immun 73:1907-1916.

Fujioka H, Akema T (2010) Lipopolysaccharide acutely inhibits proliferation of neural precursor cells in the dentate gyrus in adult rats. Brain Res 1352:35-42.

Giuliani F, Hader W, Yong VW (2005) Minocycline attenuates T cell and microglia activity to impair cytokine production in T cell-microglia interaction. J Leukoc Biol 78:135-143.

Hammond TR, Robinton D, Stevens B (2018) Microglia and the brain: complementary partners in development and disease. Annu Rev Cell Dev Biol 34:523-544.

Hauss-Wegrzyniak B, Lukovic L, Bigaud M, Stoeckel ME (1998) Brain inflammatory response induced by intracerebroventricular infusion of lipopolysaccharide: an immunohistochemical study. Brain Res 794:211-224.

Hu X, Li P, Guo Y, Wang H, Leak RK, Chen S, Gao Y, Chen J (2012) Microglia/macrophage polarization dynamics reveal novel mechanism of injury expansion after focal cerebral ischemia. Stroke 43:3063-3070.
Jacobs AT, Ignarro LJ (2001) Lipopolysaccharide-induced expression of interferon-beta mediates the timing of inducible nitric-oxide synthase induction in RAW 264.7 macrophages. J Biol Chem 276:47950-47957.

Kim BJ, Kim MJ, Park JM, Lee SH, Kim YJ, Ryu S, Kim YH, Yoon BW (2009) Reduced neurogenesis after suppressed inflammation by minocycline in transient cerebral ischemia in rat. J Neurol Sci 279:70-75.

Kirn J, O'Loughlin B, Kasparian S, Nottebohm F (1994) Cell death and neuronal recruitment in the high vocal center of adult male canaries are temporally related to changes in song. Proc Natl Acad Sci U S A 91:7844-7848.

Kizil C, Kaslin J, Kroehne V, Brand M (2012) Adult neurogenesis and brain regeneration in zebrafish. Dev Neurobiol 72:429-461.

Kobayashi K, Imagama S, Ohgomori T, Hirano K, Uchimura K, Sakamoto K, Hirakawa A, Takeuchi H, Suzumura A, Ishiguro N, Kadomatsu K (2013) Minocycline selectively inhibits M1 polarization of microglia. Cell Death Dis 4:e525.

Kohman RA, Rhodes JS (2013) Neurogenesis, inflammation and behavior. Brain Behav Immun 27:22-32.

Konigsmark B (1970) The counting of neurons. In: Contemporary research methods in neuroanatomy (Nauta W, Ebbeson S, eds), pp 315-340. New York: Springer.

Kuo PC, Scofield BA, Yu IC, Chang FL, Ganea D, Yen JH (2016) Interferon-beta modulates inflammatory response in cerebral ischemia. J Am Heart Assoc 5:e002610.

Kyritsis N, Kizil C, Zocher S, Kroehne V, Kaslin J, Freudenreich D, Iltzsche A, Brand M (2012) Acute inflammation initiates the regenerative response in the adult zebrafish brain. Science 338:13531356.

Larson TA (2018) Sex steroids, adult neurogenesis, and inflammation in CNS homeostasis, degeneration, and repair. Front Endocrinol (Lausanne) 9:205.

Larson TA, Thatra NM, Lee BH, Brenowitz EA (2014) Reactive neurogenesis in response to naturally occurring apoptosis in an adult brain. J Neurosci 34:13066-13076.

Larson TA, Thatra NM, Hou D, Hu RA, Brenowitz EA (2019) Seasonal changes in neuronal turnover in a forebrain nucleus in adult songbirds. J Comp Neurol 527:767-779.

Lee JC, Cho GS, Kim HJ, Lim JH, Oh YK, Nam W, Chung JH, Kim WK (2005) Accelerated cerebral ischemic injury by activated macrophages/microglia after lipopolysaccharide microinjection into rat corpus callosum. Glia 50:168-181.

Loram LC, Sholar PW, Taylor FR, Wiesler JL, Babb JA, Strand KA, Berkelhammer D, Day HE, Maier SF, Watkins LR (2012) Sex and estradiol influence glial pro-inflammatory responses to lipopolysaccharide in rats. Psychoneuroendocrinology 37:1688-1699.

Mannoji H, Yeger H, Becker LE (1986) A specific histochemical marker (lectin Ricinus communis agglutinin-1) for normal human microglia, and application to routine histopathology. Acta Neuropathol 71:341-343.

Marshall GP 2nd, Deleyrolle LP, Reynolds BA, Steindler DA, Laywell ED (2014) Microglia from neurogenic and non-neurogenic regions display differential proliferative potential and neuroblast support. Front Cell Neurosci 8:180.

Meitzen J, Perkel DJ, Brenowitz EA (2007) Seasonal changes in intrinsic electrophysiological activity of song control neurons in wild song sparrows. J Comp Physiol A Neuroethol Sens Neural Behav Physiol 193:677-683.

Meitzen J, Thompson CK, Choi H, Perkel DJ, Brenowitz EA (2009) Time course of changes in Gambel's white-crowned sparrow song behavior following transitions in breeding condition. Horm Behav 55:217-227.

Pedersen AL, Brownrout JL, Saldanha CJ (2017a) Central administration of indomethacin mitigates the injury-induced upregulation of aromatase expression and estradiol content in the zebra finch brain. Endocrinology 158:2585-2592.

Pedersen AL, Gould CJ, Saldanha CJ (2017b) Activation of the peripheral immune system regulates neuronal aromatase in the adult zebra finch brain. Sci Rep 7:10191. 
Perez-Pouchoulen M, VanRyzin JW, McCarthy MM (2015) Morphological and phagocytic profile of microglia in the developing rat cerebellum. eNeuro 2:ENEURO.0036-15.2015.

Prinz M, Priller J (2014) Microglia and brain macrophages in the molecular age: from origin to neuropsychiatric disease. Nat Rev Neurosci 15:300-312.

Reiner A, Perkel DJ, Bruce LL, Butler AB, Csillag A, Kuenzel W, Medina L, Paxinos G, Shimizu T, Striedter G, Wild M, Ball GF, Durand S, Güntürkün O, Lee DW, Mello CV, Powers A, White SA, Hough G, Kubikova L, et al. (2004) Revised nomenclature for avian telencephalon and some related brainstem nuclei. J Comp Neurol 473:377-414.

Ritzel RM, Capozzi LA, McCullough LD (2013) Sex, stroke, and inflammation: the potential for estrogen-mediated immunoprotection in stroke. Horm Behav 63:238-253.

Scott BB, Lois C (2007) Developmental origin and identity of song system neurons born during vocal learning in songbirds. J Comp Neurol 502:202-214.

Semmler A, Okulla T, Sastre M, Dumitrescu-Ozimek L, Heneka MT (2005) Systemic inflammation induces apoptosis with variable vulnerability of different brain regions. J Chem Neuroanat 30:144157.

Shigemoto-Mogami Y, Hoshikawa K, Goldman JE, Sekino Y, Sato K (2014) Microglia enhance neurogenesis and oligodendrogenesis in the early postnatal subventricular zone. J Neurosci 34:2231-2243.

Sierra A, Encinas JM, Deudero JJP, Chancey JH, Enikolopov G, Overstreet-Wadiche LS, Tsirka SE, Maletic-Savatic M (2010) Microglia shape adult hippocampal neurogenesis through apoptosis-coupled phagocytosis. Cell Stem Cell 7:483-495.

Smith GT, Brenowitz EA, Wingfield JC (1997) Roles of photoperiod and testosterone in seasonal plasticity of the avian song control system. J Neurobiol 32:426-442.

Srinivasan A, Roth KA, Sayers RO, Shindler KS, Wong AM, Fritz LC, Tomaselli KJ (1998) In situ immunodetection of activated caspase3 in apoptotic neurons in the developing nervous system. Cell Death Differ 5:1004-1016.

Strahan JA, Walker WH 2nd, Montgomery TR, Forger NG (2017) Minocycline causes widespread cell death and increases microglial labeling in the neonatal mouse brain. Dev Neurobiol 77:753766.
Thompson CK, Brenowitz EA (2008) Caspase inhibitor infusion protects an avian song control circuit from seasonal-like neurodegeneration. J Neurosci 28:7130-7136.

Thompson CK, Bentley GE, Brenowitz EA (2007) Rapid seasonal-like regression of the adult avian song control system. Proc Natl Acad Sci U S A 104:15520-15525.

Tobin MK, Bonds JA, Minshall RD, Pelligrino DA, Testai FD, Lazarov O (2014) Neurogenesis and inflammation after ischemic stroke: what is known and where we go from here. J Cereb Blood Flow Metab 34:1573-1584.

Tramontin AD, Smith GT, Breuner CW, Brenowitz EA (1998) Seasonal plasticity and sexual dimorphism in the avian song control system: stereological measurement of neuron density and number. J Comp Neurol 396:186-192.

Tramontin AD, Hartman VN, Brenowitz EA (2000) Breeding conditions induce rapid and sequential growth in adult avian song control circuits: a model of seasonal plasticity in the brain. $\mathrm{J}$ Neurosci 20:854-861.

Vallières L, Campbell IL, Gage FH, Sawchenko PE (2002) Reduced hippocampal neurogenesis in adult transgenic mice with chronic astrocytic production of interleukin-6. J Neurosci 22:486-492.

Vartanian KB, Stevens SL, Marsh BJ, Williams-Karnesky R, Lessov NS, Stenzel-Poore MP (2011) LPS preconditioning redirects TLR signaling following stroke: TRIF-IRF3 plays a seminal role in mediating tolerance to ischemic injury. J Neuroinflammation 8:140.

Vegeto E, Bonincontro C, Pollio G, Sala A, Viappiani S, Nardi F, Brusadelli A, Viviani B, Ciana P, Maggi A (2001) Estrogen prevents the lipopolysaccharide-induced inflammatory response in microglia. J Neurosci 21:1809-1818.

Villa A, Vegeto E, Poletti A, Maggi A (2016) Estrogens, neuroinflammation, and neurodegeneration. Endocr Rev 37:372-402.

Wood W, Martin P (2017) Macrophage functions in tissue patterning and disease: new insights from the fly. Dev Cell 40:221-233.

Wu VW, Nishiyama N, Schwartz JP (1998) A culture model of reactive astrocytes: increased nerve growth factor synthesis and reexpression of cytokine responsiveness. J Neurochem 71:749-756.

Wynn TA, Chawla A, Pollard JW (2013) Macrophage biology in development, homeostasis and disease. Nature 496:445-455.

Zhao J, Bi W, Xiao S, Lan X, Cheng X, Zhang J, Lu D, Wei W, Wang Y, Li H, Fu Y, Zhu L (2019) Neuroinflammation induced by lipopolysaccharide causes cognitive impairment in mice. Sci Rep 9:5790. 